\title{
Effect of vitamin E, Andrographis paniculata and turmeric as dietary antioxidant supplementation on lipid and color stability of goat meat.
}

\begin{abstract}
This study was carried out to determine the effects of dietary antioxidant supplementations of vitamin E, Andrographis paniculata Nees and Curcuma longa L. on lipid and color stability of chevon. Four dietary treatments of eight goats each were randomly assigned to basal diet $70 \%$ concentrate and $30 \%$ oil palm fronds $(\mathrm{CN}), \mathrm{CN}+400 \mathrm{mg} / \mathrm{kg}$ vitamin $\mathrm{E}(\mathrm{VE}), 0.5 \%$ turmeric (TU) or $0.5 \%$ Andrographis paniculata (AP). After 14 weeks of feeding, the goats were slaughtered and goat meat was sampled, then vacuum- packaged and conditioned for three post mortem aging periods (0, 7 and 14 days) in a chiller $\left(4{ }^{\circ} \mathrm{C}\right)$. Meat tenderness was improved $(\mathrm{P}<0.05)$ at 14 days aging in biceps femoris $(\mathrm{BF})$ muscle. All antioxidant supplements improved $(\mathrm{P}<0.05)$ color of the meat. The supplementation of dietary antioxidants had significantly ( $\mathrm{P}<0.05$ ) improved the $\mathrm{L}$ (lightness), a (redness), b (yellowness) as well as the chroma and hue angle values. Post mortem aging periods significantly $(\mathrm{P}<0.05)$ influenced on redness, yellowness, chroma and hue angle. Similarly, the thiobarbituric acid reactive substances (TBARS) value of the chevon was shown to be affected by the dietary supplementation of antioxidants. It is concluded that TU and AP are potential dietary antioxidant supplements like VE, for the purpose of color stability and preventing of lipid oxidation, particularly in post mortem aging periods of the biceps femoris muscle.
\end{abstract}

Keyword: Goat meat color; Lipid oxidation; Antioxidant. 